\title{
Pour en lire plus : Nature vivante et âme pacifiée
}

Nathalie Calmé

\section{(2) OpenEdition \\ Journals}

Édition électronique

URL : http://journals.openedition.org/ere/573

DOI : $10.4000 /$ ere. 573

ISSN : 2561-2271

Éditeur

Centr'ERE

Référence électronique

Nathalie Calmé, «Pour en lire plus : Nature vivante et âme pacifiée », Éducation relative à

l'environnement [En ligne], Volume 12 | 2015, mis en ligne le 20 mai 2015, consulté le 23 septembre

2020. URL : http://journals.openedition.org/ere/573 ; DOI : https://doi.org/10.4000/ere.573 


\title{
Pour en lire plus : Nature vivante et âme pacifiée
}

\author{
Nathalie Calmé
}

\section{RÉFÉRENCE}

Mohammed Taleb (2014). Nature vivante et Âme pacifiée. La Bégude de Mazence : Arma Artis, $248 \mathrm{p}$.

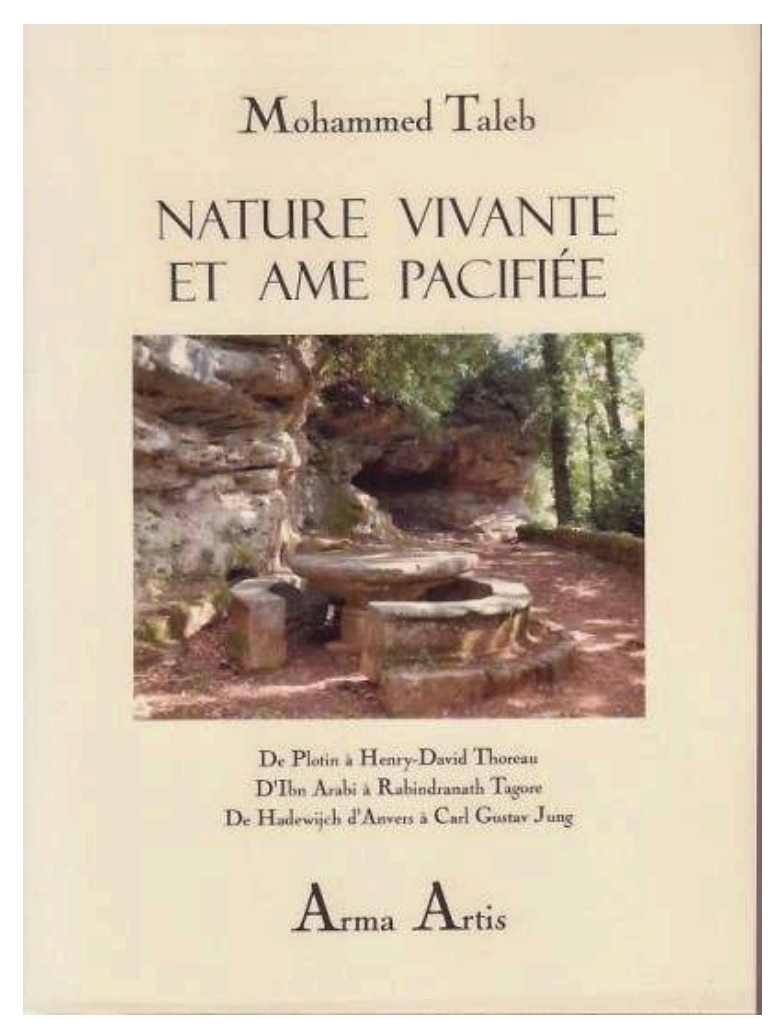


1 Cet ouvrage intéressera tous ceux et celles qui pensent que la philosophie, la spiritualité ou l'art ne doivent pas être les parents pauvres de la culture générale des acteurs et actrices de l'éducation, de la formation et de la sensibilisation relatives à l'environnement. L'auteur, qui est lui-même formateur et enseignant, propose une exploration de l'histoire de la philosophie et de la métaphysique, de la littérature et de la science, de la psychologie et de la poésie, en dessinant les esquisses de 49 portraits de personnages issus de la Grèce antique, de la civilisation arabo-musulmane, de la Renaissance européenne, de l'Inde, du Japon, de la tradition alchimique, du romantisme, de la psychologie et de l'écologie contemporaine. Le titre de l'ouvrage donne la clé pour comprendre le sens de ce panorama : il y a un continuum entre la vie intérieure et la Nature vivante, entre les paysages de l'âme et notre environnement.

2 Mohammed Taleb écrit : « La vie de l'âme n'est pas limitée à la sphère de l'intime, mais se déploie jusqu'aux confins de l'univers. Par l'imagination vraie (l'imaginatio vera de Paracelse) et la symbolisation, la psyché est capable de se dilater, et l'âme de retrouver les chemins de l'Âme du monde, qu'en Islam on appelle nafs al-kulliyya, l'Âme universelle ou totale. De même, la vie de la Nature n'est pas enclose dans la matérialité du minéral, du végétal et de l'animal. À travers ces écosymboles que sont les quatre éléments (la Terre, l'Eau, l'Air et le Feu), la Nature se révèle présence intérieure à l'âme. L'anthropologie, en vérité, est d'abord une cosmo-anthropologie, car l'univers, subtilement, est en nous. » Ce parcours n'est pas éthiquement ni politiquement neutre. En fait, à partir du paradigme de l'écopsychologie et d'une écologie spirituelle, l'auteur nous invite à entrer dans une militance, celle qui vise au dépassement du "désenchantement capitaliste de la Nature» et de la "profanation de l'environnement » que cette « modernité » propage " avec son lot d'injustices sociales, de domination des peuples». La philosophie de l'auteur se situe à l'interface de plusieurs sensibilités présentes en éducation relative à l'environnement, comme les courants naturaliste, holistique, critique, culturel, écoformateur...

3 Parmi les figures présentées: Pythagore; Plotin Le Prophète Mohammed; François d'Assise; Paracelse; Goethe; Henry David Thoreau; Khalil Gibran; Rabindranath Tagore ; Alfred North Whitehead ; Carl Gustav Jung; Theodore Roszak ; Paul Shepard ; Gilbert Durand. Chaque portrait, outre une heureuse citation, comprend d'utiles orientations bibliographiques. Un index des noms permet enfin de naviguer dans ce dense ouvrage.

4 L'ouvrage peut être commandé en envoyant un courrier électronique à l'adresse suivante : lesingulieruniversel@yahoo.fr

\section{AUTEURS}

NATHALIE CALMÉ

Écrivaine et journaliste 